Revista de CIENCIAS AMBIENTALES Tropical Journal of Environmental Sciences
Revista de Ciencias Ambientales (Trop J Environ Sci) e-ISSN: 2215-3896

(Julio-Diciembre, 2019). Vol 53(2): 156-165 DOI: https://doi.org/10.15359/rca.53-2.9 Open Access: www.revistas.una.ac.cr/ambientales e-mail: revista.ambientales@una.ac.cr Bolaños-Montero R.

\title{
BIOGRAFÍA
}

\section{Joseph A. Tosi: ecólogo forestal y visionario promotor de la conservación y el desarrollo}

\author{
Joseph A. Tosi: Forestry Ecologist and Visionary Promoter of Conservation and \\ Development
}

Rafael Bolaños Montero ${ }^{a}$

\section{Introducción}

El manejo de los recursos naturales en la Costa Rica de la década de 1960 era muy distinto del que se insinúa en la de 1990 y se consolida hacia el presente. El Dr. Joseph Tosi Jr., ecólogo forestal, como solía presentarse para efectos técnicos, norteamericano de nacimiento y costarricense por decisión, conoció y vivió esta realidad del país, y hasta puede decirse que fue uno de los científicos quienes influyeron en esta transformación hacia una cultura que valorara y apreciara la riqueza e importancia de los recursos naturales del país. Tosi mencionaba que, junto con unos pocos amigos, fundó el Centro Científico Tropical (CCT) a inicios del decenio de 1960, precisamente por la carencia del enfoque científico que existía en las instituciones nacionales,

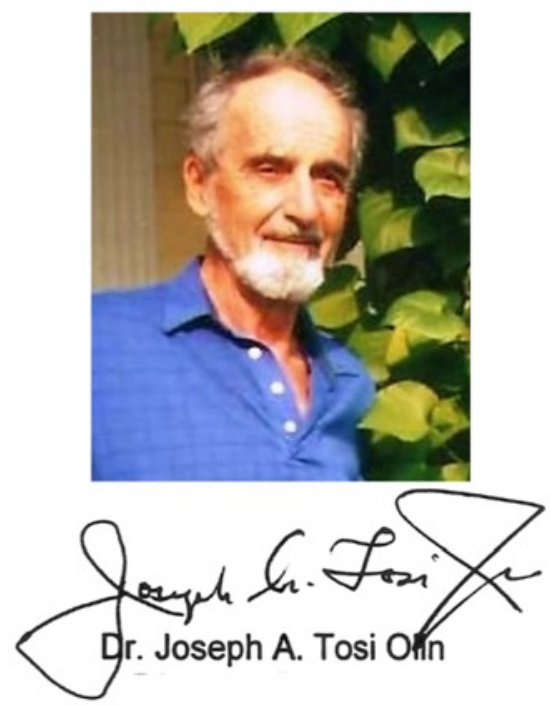
especialmente hacia el bosque, el cual era subvalorado y hasta despreciado como recurso.

La impresión del abundante recurso forestal y su biodiversidad, que le llamó tanto la atención al conocer el país en 1950, eran motivo de asombro, al vivir la cruda realidad del despilfarro y de la destrucción del valiosísimo recurso, aun con el apoyo mismo del Gobierno y de entes financieros internacionales, con una visión cortoplacista y marcadamente errada de lo que debería llamarse planificación del uso de la tierra y desarrollo. Entonces, la mal llamada "ley de mejoras" que aplicaba el país premiaba, con el derecho de escritura de terrenos libres,

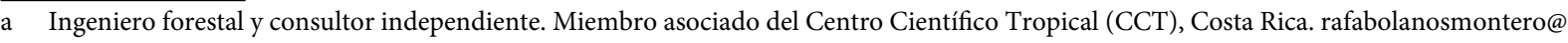
gmail.com

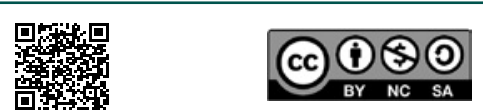




\section{Revista de CIENCIAS AMBIENTALES Tropical Journal of Environmental Sciences}

Revista de Ciencias Ambientales (Trop J Environ Sci) e-ISSN: 2215-3896

(Julio-Diciembre, 2019). Vol 53(2): 156-165 DOI: https://doi.org/10.15359/rca.53-2.9

Open Access: www.revistas.una.ac.cr/ambientales e-mail: revista.ambientales@una.ac.cr Bolaños-Montero R.

a quienes hubieran deforestado el bosque nativo y lo hubiesen transformado en agricultura de subsistencia o potreros de ganadería extensiva.

Tosi luchó contra eso, plasmó en informes técnicos - basados en estudios de campo- las pautas que debía seguir el país; dictó charlas y conferencias, y solicitó citas con políticos, incluyendo mandatarios, para tratar de cambiar esta equívoca idea de desarrollo y del arraigado concepto de que Costa Rica era un país de vocación agropecuaria. Recuerdo haberle acompañado en 2 ocasiones a Zapote, ante el presidente Rodrigo Carazo Odio, por allá de 1980-1981, porque le iba a exponer la necesidad de crear áreas protegidas, una de las cuales sería el Parque Nacional Volcán Arenal. Aunque al inicio algunos de sus informes técnicos simplemente quedaron "engavetados" por el Gobierno, en la parte postrera de su vida profesional atestiguó, con gran júbilo, el cambio de rumbo de la nación hacia la valoración y protección de sus recursos naturales.

\section{Su formación académica}

Joseph Andrew Tosi Olin nació el 1. ${ }^{\circ}$ de julio de 1921 en Massachusetts. Su padre fue ingeniero civil, de origen italiano, en tanto que su madre provenía de una familia sueca dedicada a la actividad gastronómica. Se casó con Mary Lu Patchen — conocida como Marilú Tosi en el mundo artístico, pues fue una destacada coreógrafa - con quien tuvo 3 hijos: Lucinda, Alex y Jonathan.

En cuanto a su formación académica, se graduó de bachiller en ciencias en el Massachusetts State College, en 1943, donde trabajó en aspectos referidos al manejo de la vida silvestre. En 1948, obtuvo una maestría forestal en la Universidad de Yale. Realizó su tesis doctoral en Puerto Rico y, en 1959, obtuvo el doctorado en geografía en la Universidad de Clark, en Massachusetts, con la tesis Forest land utilization in western Puerto Rico.

Durante su estancia en Puerto Rico, estableció contacto con el Dr. Leslie R. Holdridge creador del sistema de clasificación ecológica de las zonas de vida del mundo-, por entonces director interino del Departamento de Recursos Naturales del Instituto Interamericano de Ciencias Agrícolas (IICA), con sede en Turrialba, Costa Rica, y quien, al percibir el currículum del joven profesional, lo invitó a integrarse al IICA. Tosi lo hizo entre 1951-1952, pero por poco tiempo, pues fue enviado como encargado y fundador del Programa Forestal para la Zona Andina, de la Organización de Estados Americanos (OEA), con sede en Lima, Perú. Permaneció ahí unos 8 años atendiendo Perú, Bolivia, Ecuador, Colombia y Venezuela.

En 1960, regresó a Costa Rica, donde residiría el resto de su vida. Ocupó el puesto que estaba dejando Holdridge como ecólogo principal en el IICA. Renunció en 1964, un tanto desmotivado con los aspectos políticos y la burocracia institucional, para dedicarse a las consultorías en el CCT, entidad que, como se dijo, contribuyó a fundar en 1962. En 1975, adoptó la nacionalidad costarricense, pues amaba este país.

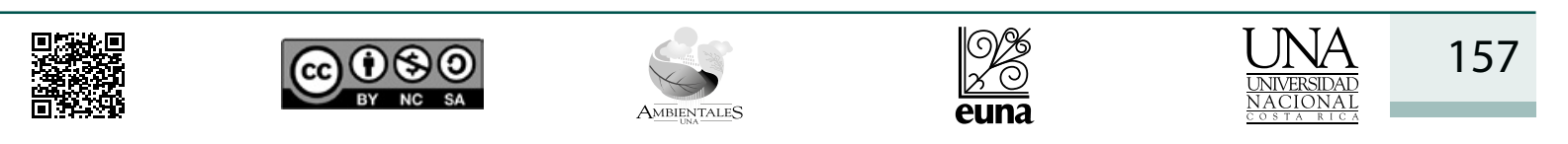




\section{Revista de CIENCIAS AMBIENTALES Tropical Journal of Environmental Sciences}

Revista de Ciencias Ambientales (Trop J Environ Sci) e-ISSN: 2215-3896

(Julio-Diciembre, 2019). Vol 53(2): 156-165 DOI: https://doi.org/10.15359/rca.53-2.9

Open Access: www.revistas.una.ac.cr/ambientales e-mail: revista.ambientales@una.ac.cr Bolaños-Montero R.

\section{Su fecunda labor desde el CCT}

En 1967, Tosi se convirtió en administrador del CCT, equivalente a director de la institución, puesto que desempeñó compartiéndolo con consultorías. Gracias a su excelente rendimiento, fue reelecto en forma reiterada hasta 1990. Durante los primeros 16 años, lo hizo ad honorem, pues el CCT no contaba con ingresos suficientes para garantizarle un salario.

Numerosos estudios de consultoría fueron realizados por el CCT, bajo la administración o posterior presidencia de Tosi, tanto dentro como fuera del país, en la mayoría de los cuales participó personalmente. Algunos fueron de trascendencia histórica para Costa Rica, como la recomendación técnica dirigida a la declaración de muchos de los parques nacionales y reservas biológicas con los que cuenta el territorio costarricense. Durante sus 42 años en la institución, fue autor o coautor de unos 140 estudios de consultoría, la mayoría de los cuales dirigió. Asimismo, llevó a cabo una gran cantidad de mapas para muchos países, a lo largo de su vida profesional, entre los que sobresalieron los referidos al uso de la tierra y las zonas de vida. Además, fue profesor de la carrera de Ingeniería Forestal en el Instituto Tecnológico de Costa Rica.

Desde el CCT, a mediados del decenio de 1960, participó junto con científicos como Robert Hunter, Alexander Skutch y el propio Holdridge en los cursos de campo con la Associated Colleges of the Midwest (ACM), que en aquel tiempo movilizaba los estudiantes y el equipo, en helicópteros, a las estaciones de campo arrendadas por el CCT, en varios lugares del país. Así, nació el hoy exitoso y consolidado programa de los cursos de campo en biología tropical de la Organización de Estudios Tropicales (OET).

Aunque Tosi no aspiraba a galardones o distinciones, se le reconoció en vida su fecunda labor, al menos, parcialmente. En tal sentido, en 1974, el Gobierno del Perú le otorgó la Orden del Mérito Agrícola, Grado de Comendador, mientras que en 1990, se le designó Miembro Honorario del Colegio de Ingenieros Agrónomos de Costa Rica. Asimismo, en el 2004, la Cámara de Turismo de Monteverde le confirió al CCT el reconocimiento como gestor y líder del ecoturismo en el país, pero es conocido que fue específicamente Tosi quien impulsó y desarrolló esta actividad para la Reserva Biológica del Bosque Nuboso Monteverde.

Admiraba, en forma integral, los bosques tropicales, no solo como ingeniero forestal, para el manejo de sus abundantes recursos madereros, sino también como biólogo, pues insistía en la importancia de la protección de la rica biota natural, la extracción de plantas medicinales y el ecoturismo, actividad en la que fue pionero en el país.

Tenía, además, gran interés por el aprovechamiento racional y la conservación del mar; por lo tanto, era un apasionado de este. Tal fue su afición por los veleros que, durante muchos años, fue propietario de uno y gozó surcando las aguas del golfo de Nicoya, así como otros lugares cercanos a Costa Rica.

Disfrutaba navegar y usar la fuerza del viento para desplazarse; utilizaba su motor solo cuando las velas no se henchían. Este pasatiempo lo desarrolló plenamente con su familia y amigos; solía competir por las carreras de regata en el golfo de Nicoya. Sin embargo, eran los viajes

(cc)




\section{Revista de CIENCIAS AMBIENTALES Tropical Journal of Environmental Sciences}

Revista de Ciencias Ambientales (Trop J Environ Sci) e-ISSN: 2215-3896

(Julio-Diciembre, 2019). Vol 53(2): 156-165 DOI: https://doi.org/10.15359/rca.53-2.9

Open Access: www.revistas.una.ac.cr/ambientales e-mail: revista.ambientales@una.ac.cr Bolaños-Montero R.

tranquilos de fin de semana los que más le atraían. Planeaba con esmero cada viaje, los horarios de mareas, el clima, sus acompañantes - que era su tripulación, pues solo no podía navegar- y la alimentación. Mirar el atardecer y sentir la brisa marina lo hacían exclamar la frase " ¡La buena vida!", dibujando una convincente sonrisa al arribar al sector de isla Negritos, sitio predilecto para pernoctar.

Por muchos años tuvo una finquita, como él le decía. Era de una media hectárea, en Sarapiquí, en la ribera del río Puerto Viejo, casi colindante con la estación La Selva, de la OET. Allí construyó una rústica casa de madera y la usaba como sitio de descanso algunos fines de semana. En este terreno, plantaba árboles, que traía de distintos lugares y países; también tenía árboles nativos maderables. Con frecuencia, invitaba a sus amigos, insistiéndoles en que debían ver los árboles que tenía allá y ufanándose siempre del desarrollo de estos, para lo que usaba el calificativo “¡Es impresionante!”. Con los años, decidió venderle el terreno a un amigo, que lo apreciara tanto como él y que no cortara los árboles.

\section{La dupla Tosi-Holdridge}

Como se indicó, Tosi tomó la iniciativa de establecer contacto con Holdridge, lo que le permitiría conocer de primera mano el sistema ecológico desarrollado por este para la clasificación de las zonas de vida del planeta. Escéptico, al principio lo cuestionaba, pero poco a poco, más bien, se convenció de la funcionalidad de ese sistema, al punto de convertirse en uno de sus mayores usuarios y promotores.

La relación con Holdridge le deparó a Tosi una larga y sincera amistad, así como una "simbiosis profesional". Personas humildes ambas, al lado de otros profesionales, fundaron el CCT, laboraron juntos por muchos años y se complementaron en sus fortalezas individuales.

Fue así como Tosi se dedicó a profundizar en el sistema propuesto por Holdridge, lo complementó, lo utilizó como base para predecir la productividad y los balances hídricos, como marco para delimitar la capacidad de uso de la tierra, al igual que como patrón para evaluar y recomendar áreas de protección. Se dedicó a levantar, con singular disfrute, mapas basados en el sistema de zonas de vida en muchos países (Figura 1). Se contabilizan unos 16 en el nivel país - a distintas escalas - y otros tantos en zonas o regiones de varias naciones.

Si se piensa en esta amistad y relación profesional Tosi-Holdridge dentro una misma y pequeña institución, como el CCT, puede decirse que la figura profesional de Tosi como científico no fue tan exaltada en su magnitud e importancia, debido al extraordinario renombre de su colega Holdridge. Más bien, Tosi era su admirador, y así lo manifestaba abiertamente, al punto de decirnos a sus técnicos — como nos llamaba - "Holdridge es un genio; es de otro planeta". Pero, a su vez, Holdridge admiraba a Tosi por su empeño, gestión y capacidad de unificar.

\begin{tabular}{|c|c|c|c|c|}
\hline 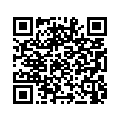 & (c) (7)(-) () & 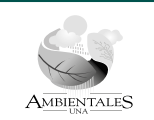 & $\frac{O \%}{2 \%}$ & 159 \\
\hline
\end{tabular}




\section{Revista de CIENCIAS AMBIENTALES Tropical Journal of Environmental Sciences}

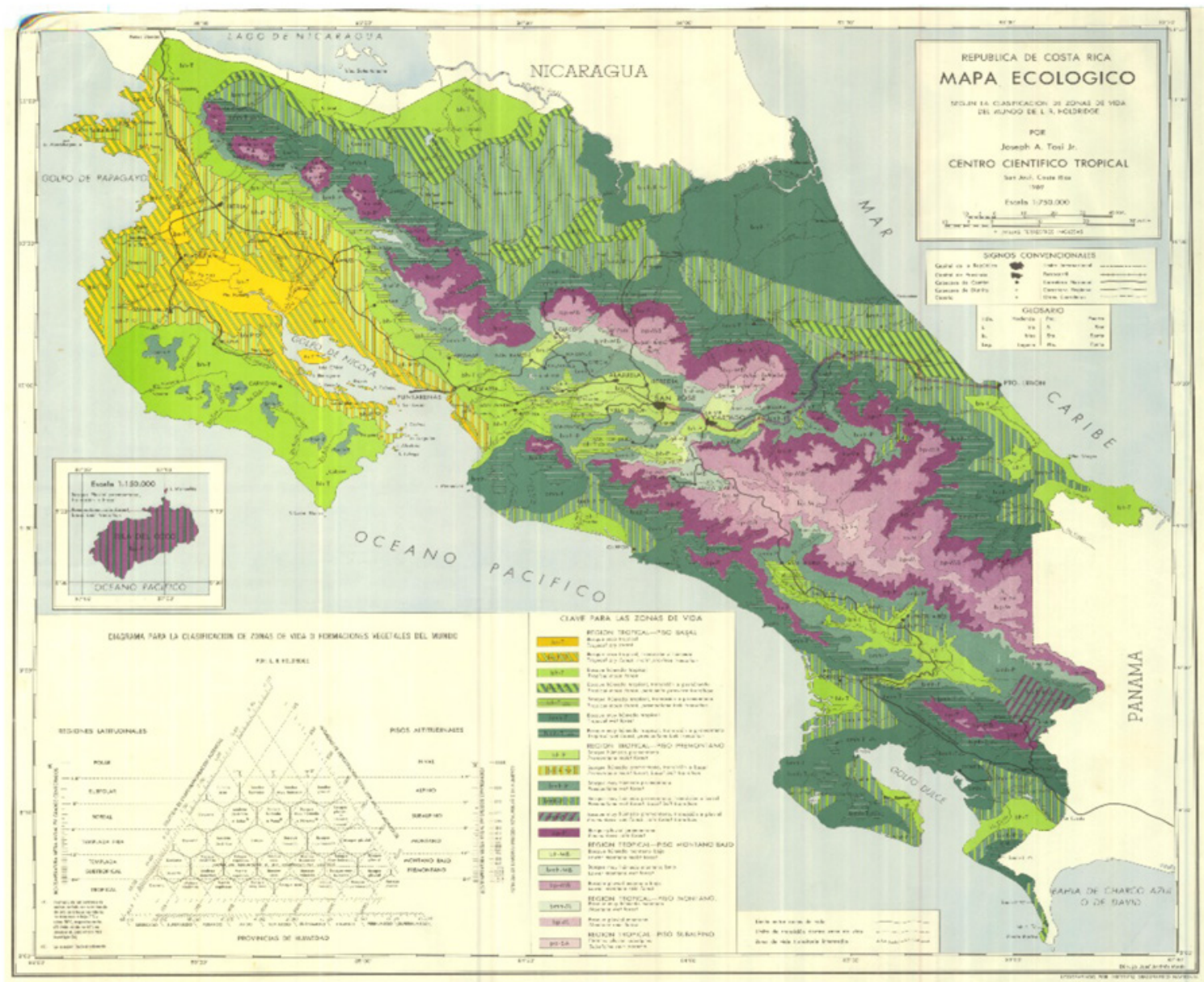

Figura 1. Primera versión del mapa ecológico de zonas de vida de Costa Rica (1969).

\section{El ordenador y visionario}

Contrario a la norma predominante de muchos científicos, que resaltan y ponen por encima sus especialidades o campos de acción, Tosi no actuaba de esta manera, sino que era multidisciplinario. Aunque criticaba mucho la ganadería y defendía el bosque para su manejo multiuso, también proponía y defendía los terrenos para que fuesen dedicados a la agricultura y la ganadería, todo basado en sus condiciones físico-climáticas. De igual forma, sugería como zonas para conservación y protección absoluta aquellas donde no era posible extraer ni un árbol para madera.

Eso sí, en el caso de Costa Rica, siempre pensó que la extraordinaria capacidad de producción de biomasa de gran parte del territorio nacional era un gran potencial que debía ser aprovechado. Así, a mediados del decenio de 1980, estuvo tratando de conseguir financiamiento

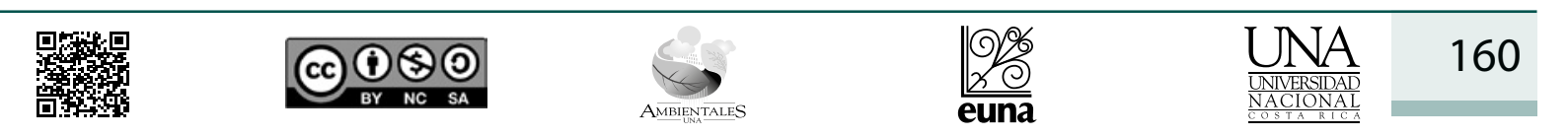




\section{Revista de CIENCIAS AMBIENTALES Tropical Journal of Environmental Sciences}

Revista de Ciencias Ambientales (Trop J Environ Sci) e-ISSN: 2215-3896 (Julio-Diciembre, 2019). Vol 53(2): 156-165 DOI: https://doi.org/10.15359/rca.53-2.9 Open Access: www.revistas.una.ac.cr/ambientales e-mail: revista.ambientales@una.ac.cr Bolaños-Montero R.

para investigar el proceso de transformar biomasa forestal como fuente de alimentación para el ganado. Más adelante, a inicios del nuevo siglo, hizo lo mismo con la opción de producir metanol a partir de la madera, como combustible vehicular. Para ello, coordinó la alianza del CCT con universidades y entes privados, pero no fue posible conseguir los fondos esperados.

En otro aspecto, de ordenar el desarrollo de proyectos relacionados con tierras, aguas, bosques e infraestructura, puede decirse que, de la mano de Tosi — su conductor por 25 años-, el CCT fue precursor de los estudios de impacto ambiental en Costa Rica, cuando aún no se les denominaba así. Entre estos se destaca, por ser pionero, la investigación de la carretera San José-Guápiles (1975), cuya recomendación derivó en la creación del Parque Nacional Braulio Carrillo. También se puede mencionar el Proyecto Hidroeléctrico Arenal (1973) o el Proyecto Hidroeléctrico Boruca (1975). En estas indagaciones, Tosi siempre aplicó una visión multidisciplinaria, con el marco ecológico de zonas de vida como patrón de ordenamiento global.

Igualmente, el investigador propuso metodologías para determinar la capacidad de uso de la tierra, lo cual hizo para Costa Rica y otros países. Además, planteó un método para la predicción o crecimiento de la cantidad de carbono almacenado en el ecosistema, usando siempre la zona de vida como la base guía de su productividad.

Tasaba muy alto el valor potencial de los recursos naturales y, sobre todo, del bosque (Figura 2). Sin embargo, él visualizaba un gran potencial para el uso recreativo, cuando esto no era contemplado. Por ejemplo, al justificar la creación de Corcovado como parque nacional en 1972 (Tosi et al., 1975), da una serie de razonamientos para procurar su fundación, sobre lo que tenía muy claro: el potencial para el turismo naturalista. En sus propias palabras, destaco en negrita las esenciales, “....birds and mammals present, as well as future generations of Costa Rican, as well as visitors from all over the world, would be assured the opportunity to experience firsthand this awe-inspiring and most complex of all primary forest ecosystems".

Me llamó aún más la atención, cuando conocí un estudio para la zona norte de Costa Rica (Holdridge y Tosi, 1968), conducido por él, que me parece histórico. Ahí se proponen áreas para agricultura y ganadería, otras para desarrollo forestal bajo manejo y unas más para protección, recreación y parques nacionales. Se capta el concepto claro que él tenía para lo recreativo y turístico: "En Costa Rica no existe todavía una política o programa oficial para la administración y manejo técnico por parte del Estado de las áreas cuyos valores principales derivan de su utilidad a la sociedad entera como: a) las cuencas de captación de aguas; b) las tierras inestables y sujetas a deslizamientos o avalanchas; c) las áreas de belleza escénica excepcional; d) las de valor científico y turístico; e) las reservas para la vida silvestre; y f) los lugares naturales y prístinos apropiados para el descanso y recreación. La falta de tal programa se ve más crítico cada año".

En este mismo estudio se plantean mapas con dichas áreas de manejo, áreas de protección y parques nacionales; estos últimos abarcan unas 164000 ha. Ahí recomienda al Gobierno un decreto que establezca esas reservas, en el cual deben estar bien definidos sus linderos, así como "la creación de un servicio forestal legalmente autorizado y competente". A pesar de que Tosi nos contaba que esta investigación, por limitar tanto el desarrollo para agricultura y ganadería,

\begin{tabular}{|c|c|c|}
\hline 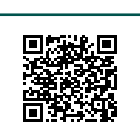 & (c) (i) () () (2) & 161 \\
\hline
\end{tabular}




\section{Revista de CIENCIAS AMBIENTALES Tropical Journal of Environmental Sciences}

Revista de Ciencias Ambientales (Trop J Environ Sci) e-ISSN: 2215-3896

(Julio-Diciembre, 2019). Vol 53(2): 156-165 DOI: https://doi.org/10.15359/rca.53-2.9 e-mail: revista.ambientales@una.ac.cr Bolaños-Montero R.

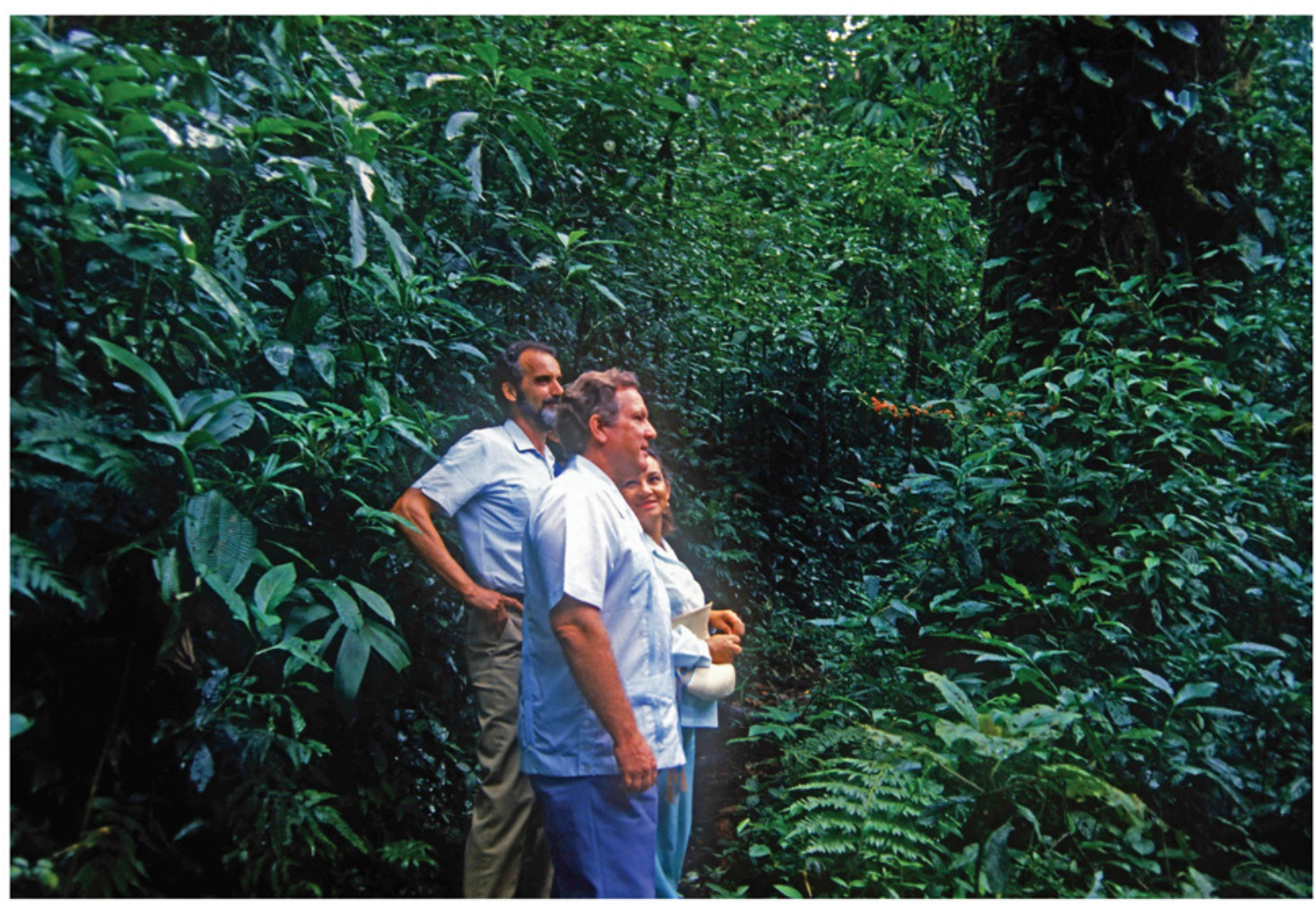

Figura 2. Tosi en una visita a la Reserva Monteverde, en 1979, en compañía del presidente de la República, Rodrigo Carazo, y la primera dama Estrella Zeledón. Foto: Mario Boza.

fue "engavetado", el año siguiente (1969) se creó la Dirección General Forestal, mediante decreto, que precisamente era una recomendación de ese trabajo.

\section{El conservacionista}

Tosi tenía muy definida la necesidad e importancia de conservar los recursos naturales, a pesar de que proponía sistemas metodológicos para cortar árboles aprovechando el bosque natural, o metodologías para emplear los terrenos en agricultura o ganadería, de acuerdo con su capacidad de utilización. En este aspecto, eran bien equilibradas sus propuestas o recomendaciones de uso. No era su apreciación personal o su preferencia, sino que ponía en práctiva argumentos muchas veces sencillos, pero irrefutables.

Conocía de suelos, agricultura, ganadería, maderas, belleza escénica, balances hídricos, biodiversidad, erosión y riesgos tanto de impactos ambientales como de economía. Todo esto lo

\begin{tabular}{|c|c|c|}
\hline 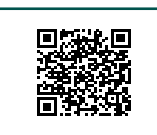 & (c) (i) @) (2) & 162 \\
\hline
\end{tabular}




\section{Revista de CIENCIAS AMBIENTALES Tropical Journal of Environmental Sciences}

Revista de Ciencias Ambientales (Trop J Environ Sci) e-ISSN: 2215-3896

(Julio-Diciembre, 2019). Vol 53(2): 156-165 DOI: https://doi.org/10.15359/rca.53-2.9 Open Access: www.revistas.una.ac.cr/ambientales e-mail: revista.ambientales@una.ac.cr Bolaños-Montero R.

sopesaba y así propuso, no solo en Costa Rica, sino en numerosos países tropicales, las recomendaciones acerca de qué hacer con zonas cubiertas o no de bosques. Varias veces le escuché —por ejemplo- esta argumentación: "Es pluvial. Van a tener un desastre si construyen un camino allí. Deben dejarlo en protección". Lo decía en forma tajante, sea que lo estuviese comentando entre colegas de un estudio o que se lo estuviera advirtiendo a un jerarca del Gobierno. No cambiaba su frase ni su tono, pues él sabía lo que estaba prediciendo.

En el país fueron muchas las áreas de conservación que él propuso establecer, de las cuales son varias las que fueron concretadas. Al respecto, mi colega Vicente Watson, también discípulo de Tosi, en un obituario, lo definió como: "el arquitecto del sistema de áreas protegidas de Costa Rica".

En efecto, entre 1972-1975, en un estudio auspiciado por la Unión Internacional para la Conservación de la Naturaleza (UICN), dirigido a la creación de áreas protegidas, como coordinador -el mismo Tosi- propuso crear 6 de estas (Tosi et al., 1975). Asimismo, años después, en otro trabajo efectuado por el CCT, bajo su dirección, recomendó el establecimiento de otras 5 áreas protegidas (Tosi et al., 1982). De igual forma, en investigaciones individuales, como la realizada para la construcción de la ruta nacional 32, se sugirió establecer una reserva biológica, que en realidad se creó con el nombre de Parque Nacional Braulio Carrillo. Otras tantas iniciativas fueron planteadas, pero no se instauraron o él las promovió en estudios no tan específicos, como aquellos para los macizos de la Cordillera Volcánica de Guanacaste, planteados en 1968 en el trabajo del CCT ya citado.

Finalmente, desde el CCT, Tosi contribuyó a fundar, junto con otros colegas ambientalistas, no solo la Asociación Costarricense para la Conservación de la Naturaleza (ASCONA), sino también la Federación Costarricense para la Conservación del Ambiente (FECON).

\section{El forestal}

Tosi siempre visualizó el manejo del bosque como una opción económica de uso de la tierra, donde las condiciones físico-climáticas de esta no fuesen aptas para otros empleos productivos más intensivos del suelo, pero que a la vez estuviesen en el marco de factibilidad de aprovechamiento y extracción. Un resumido e ilustrado folleto que respalda esta visión y tal convencimiento es su publicación Bosques pequeños bien manejados producen dinero, sugestivo y doméstico título, que sin duda representa bien su forma de ser, sencilla y directa.

Con frecuencia comentaba a sus técnicos forestales del CCT que la institución debía tener su propio bosque para manejo, pues la Reserva Biológica de Monteverde no tenía ese fin. Fue así como, a mediados de la década de 1990, logró que la señora Jeananne Patterson le donara al CCT un área boscosa en Sarapiquí (KELADY), donde se ejecutó, durante algunos años, un proyecto de manejo del bosque natural, por él conducido.

Sin duda, otro estudio de suma importancia en la vida del CCT fue el proyecto Palcazú, en Perú. Allí Tosi propuso y la USAID financió, en 1982, un modelo de manejo de bosque natural, basado en la investigación de su colega Gary Hartshorn, sobre la dinámica de renovación del bosque, a partir de los claros generados por la caída de árboles maduros (gaps). Lo visualizó

\begin{tabular}{|c|c|c|}
\hline 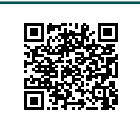 & (c) (i) (5) & 163 \\
\hline
\end{tabular}




\section{Revista de CIENCIAS AMBIENTALES Tropical Journal of Environmental Sciences}
Revista de Ciencias Ambientales (Trop J Environ Sci) e-ISSN: 2215-3896
(Julio-Diciembre, 2019). Vol 53(2): 156-165 DOI: https://doi.org/10.15359/rca.53-2.9 Open Access: www.revistas.una.ac.cr/ambientales e-mail: revista.ambientales@una.ac.cr Bolaños-Montero R.

como fajas de corta a tala rasa. Esto implicó más de 4 años de labores de campo, a cargo de un importante número de consultores, bajo la dirección del mismo Tosi. Gracias a este proyecto, el CCT logró un ingreso económico suficiente para adquirir sus propias oficinas. Se desarrolló entre los años 1984 y 1988, prosiguió un poco más, pero en forma parcial y sin labor en campo, pues la guerrilla de Sendero Luminoso irrumpió en el Valle Palcazú, donde se desenvolvían sus alcances y se debió abandonar por problemas de seguridad.

\section{El jefe amable}

Tosi era una persona humilde, muy austera, honesta, tímida para hablar en público, de carácter afable, pero, a la vez, muy drástico y directo en sus convicciones. Siempre criticaba la mediocridad, tanto como la burocracia. Era sencillo en su forma de ser, no se preocupaba por las apariencias y, por ello, rara vez se le veía vestido con traje formal y nunca en un vehículo lujoso. No se le observaba estresado, a pesar de los no escasos problemas personales o laborales. No faltó su radio en la oficina, para escuchar a diario música clásica. De igual modo, permanecía cerca su taza de café, que acudía a llenar con alguna frecuencia a la cocina del edificio, donde aprovechaba unos minutos para charlar con quien estuviese en ese momento, en el pequeño y más importante sitio de minireuniones sin protocolo, pero que a menudo derivaban en acuerdos importantes entre colegas o visitantes.

En realidad, fue un jefe poco común, pues no imponía ni exigía. Se ganaba el respeto con su forma amable y cordial de solicitar lo que requería. Tampoco estaba atento a mirar los horarios de llegada y salida; bastaba con que se hiciera el trabajo. Sacaba su tiempo para escuchar a las personas de su alrededor y no hacía distinción por estatus social ni económico.

Poseía un conocimiento extraordinario acerca de la geografía mundial, no solo por su preparación académica o porque durante su activa vida profesional hizo gran cantidad de consultorías por los trópicos del planeta, sino también debido a que era asiduo lector. Quizá por ello poseía la cualidad de conversar y opinar a profundidad sobre cualquier tema. Entre todo el bagaje de conocimientos, sobresalían sus continuos comentarios sobre la economía mundial, los recursos naturales, la sobrepoblación, los liderazgos políticos, la ecología y el desarrollo, el uso de la tierra, el clima, los recursos minerales mundiales, la salud humana, entre otros.

Siempre que viajaba, ya fuera al extranjero o al mar en un fin de semana, llevaba consigo un libro o una revista nueva para leer.

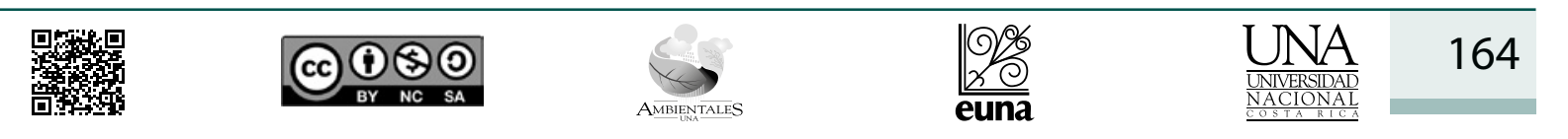




\section{Revista de CIENCIAS AMBIENTALES Tropical Journal of Environmental Sciences}

Revista de Ciencias Ambientales (Trop J Environ Sci) e-ISSN: 2215-3896

(Julio-Diciembre, 2019). Vol 53(2): 156-165 DOI: https://doi.org/10.15359/rca.53-2.9 Open Access: www.revistas.una.ac.cr/ambientales e-mail: revista.ambientales@una.ac.cr Bolaños-Montero R.

\section{El final de su vida}

Tosi se mantuvo activo durante toda su vida, con excepción de unos pocos meses al final del 2006, cuando dejó de asistir a la oficina y canceló sus frecuentes viajes de fin de semana por el golfo de Nicoya.

Cabe señalar que en el 2004 se le detectó un incipiente cáncer de garganta. Después de indagar en Internet sobre opciones de curas naturales, un día me pidió que le consiguiera unas hojas de guanábana, las cuales le traje de San Carlos, provenientes de un árbol de crecimiento orgánico. Las puso a secar, las molió y empezó a tomar el preparado, pero también decidió consumir fruta de guanábana, con todo y cáscara. Unos 3 meses después me dio la noticia de que ya no tenía cáncer.

Sin embargo, tiempo después, se manifestaron otros problemas de salud, por lo que recibió tratamiento médico, pero empezaron las complicaciones, el sistema renal le falló y comenzó a hincharse.

Esto le impidió volver a la oficina, por lo que solicitó que le llevaran la correspondencia a su casa, donde se le veía leyendo, como lo hizo toda su vida. A pesar de que su estado empeoraba, seguía leyendo, y en pocas semanas falleció. Esto ocurrió el 2 de diciembre del 2006, a los 85 años de edad. Con ello, y tras una vida de infatigable actividad, quedaron inconclusos un libro sobre zonas de vida y el proyecto del metanol.

Como lo había comentado varias veces, su deseo era morir en su velero, en altamar, pero las circunstancias impidieron complacerlo. En todo caso, sí manifestó que cremaran sus restos y lanzaran sus cenizas en el golfo de Nicoya; así se hizo.

\section{Referencias}

Holdridge, L. y Tosi, J. (1968). Investigación preliminar de la Zona Norte de las provincias de Alajuela y Heredia, Costa Rica. San José, Costa Rica: Centro Científico Tropical. Oficina de Planificación de la Presidencia de la República. BID.

Tosi, J., Vaughan, C. y Skutch, A. (1975). Áreas potenciales para establecer parques nacionales, reservas biológicas y refugios de animales silvestres en Costa Rica: Un estudio de prioridades. (Informe preparado para el Servicio de Parques Nacionales, Ministerio de Agricultura y Ganadería). San José, Costa Rica: Centro Científico Tropical.

Tosi, L., Ramírez, M. y Lewis, J. (1982). Áreas potenciales para la conservación de recursos naturales en Costa Rica. Evaluación del sistema actual de parques nacionales y reservas equivalentes. Nuevas unidades de conservación. (Estudio ecológico integral de la Zona Noreste). San José, Costa Rica: Centro Científico Tropical.

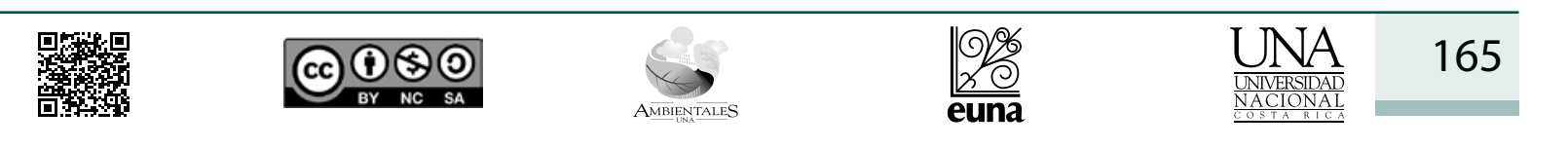

